\title{
Perivascular Fibro-Adipogenic Progenitor Tracing during Post-Traumatic 0steoarthritis
}

Takashi Sono, ${ }^{* \dagger}$ Ching-Yun Hsu, ${ }^{*}$ Yiyun Wang, ${ }^{*}$ Jiajia Xu, ${ }^{*}$ Masnsen Cherief, ${ }^{*}$ Simone Marini, ${ }^{\ddagger}$ Amanda K. Huber, Sarah Miller, ${ }^{*}$ Bruno Péault, ${ }^{\S}$ Benjamin Levi, ${ }^{*}$ and Aaron W. James ${ }^{* \S}$

From the Department of Pathology, ${ }^{*}$ Johns Hopkins University, Baltimore, Maryland; the Department of Orthopedic Surgery, ${ }^{\dagger}$ Graduate School of Medicine, Kyoto University, Kyoto, Japan; the Section of Plastic Surgery, ${ }^{\ddagger}$ Department of Surgery, University of Michigan, Ann Arbor, Michigan; and the Department of Orthopaedic Surgery and the Orthopaedic Hospital Research Center, ${ }^{\S}$ UCLA and Orthopaedic Hospital, Los Angeles, California

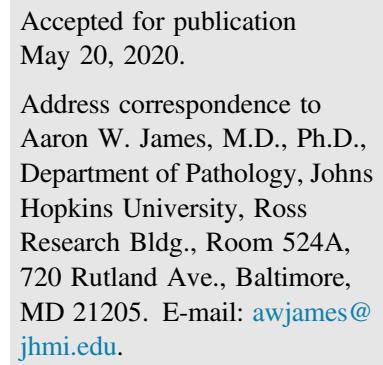

\begin{abstract}
Perivascular mural cells surround capillaries and microvessels and have diverse regenerative or fibrotic functions after tissue injury. Subsynovial fibrosis is a well-known pathologic feature of osteoarthritis, yet transgenic animals for use in visualizing perivascular cell contribution to fibrosis during arthritic changes have not been developed. Here, inducible $P d g f r a-C r e E R^{\top 2}$ reporter mice were subjected to jointdestabilization surgery to induce arthritic changes, and cell lineage was traced over an 8-week period with a focus on the joint-associated fat pad. Results showed that, at baseline, inducible Pdgfra reporter activity highlighted adventitial and, to a lesser extent, pericytic cells within the infrapatellar fat pad. Joint-destabilization surgery was associated with marked fibrosis of the infrapatellar fat pad, accompanied by an expansion of perivascular Pdgfra-expressing cellular descendants, many of which adopted $\alpha$-smooth muscle actin expression. Gene expression analysis of microdissected infrapatellar fat pad confirmed enrichment in membrane-bound green fluorescent protein/Pdgfra-expressing cells, along with a gene signature that corresponded with injury-associated fibro-adipogenic progenitors. Our results highlight dynamic changes in joint-associated perivascular fibro-adipogenic progenitors during osteoarthritis. (Am J Pathol 2020, 190: 1909-1920; https://doi.org/10.1016/j.ajpath.2020.05.017)
\end{abstract}

Perivascular mural cells surround capillaries and microvessels, and have various regenerative or fibrotic functions after tissue injury. In addition to regulation of angiogenesis, ${ }^{1}$ mural cells demonstrate tissue-intrinsic regenerative properties, ${ }^{2,3}$ but also contribute to organ fibrosis, such as in the kidney, ${ }^{4}$ lung, ${ }^{5,6}$ liver, ${ }^{7,8}$ or heart. ${ }^{9}$ Indeed, various lineagetracing strategies have been used for the identification of perivascular mural cells that contribute to organ fibrosis, including cells expressing FOXD1 ${ }^{10}$ and GLI1. ${ }^{4}$ Thus, perivascular cells (or more likely subsets of mural cells within vessel walls) can demonstrate profibrotic features after tissue injury.

Platelet-derived growth factor receptor $\alpha(P D G F R A)$ has been previously used for the identification of a bone marrow-resident skeletal progenitor cell population, ${ }^{11}$ or more generically as a marker of mesenchymal stem/stromal cells. ${ }^{11}$ PDGFRA-expressing progenitor cells within skeletal muscle are also commonly referred to as fibro-adipogenic progenitors (FAPs), ${ }^{12}$ given their ability to give rise to fibroblasts and adipocytes after skeletal muscle injury. ${ }^{13}$ In prior observations, Pdgfra-CreER ${ }^{\mathrm{T} 2} ; \mathrm{mT} / \mathrm{mG}$ reporter animals were useful for highlighting subsets of perivascular

Supported by the NIH/National Institute of Arthritis and Musculoskeletal and Skin Diseases grants R01 AR070773 (A.W.J.) and K08 AR068316 (A.W.J.); NIH/National Institute of Dental and Craniofacial Research grant R21 DE027922 (A.W.J.); US Army Medical Research Acquisition Activity (USAMRAA) grants W81XWH-180109121 (A.W.J.), W81XWH-18-10336 (A.W.J.), W81XWH-18-10613 (A.W.J.), and W81XWH-18-1-0653 (B.L.); American Cancer Society (ACS) Research Scholar grant RSG-18027-01-CSM (A.W.J.); the Maryland Stem Cell Research Foundation (A.W.J.); MTF Biologics (A.W.J.); NIH grants R01GM123069 (B.L.) and R01AR071379 (B.L.); and the ACS Clowes Award (B.L.).

Disclosures: A.W.J. obtains research support and is a member of the scientific advisory board for Novadip Biosciences for work unrelated to the current project.

T.S. and C.-Y.H. contributed equally to this work.

The content is solely the responsibility of the authors and does not necessarily represent the official views of the NIH, the Department of Defense, or the U.S. Army. 
cells that would mobilize from the vascular wall during new tissue formation within s.c. adipose tissue. ${ }^{14}$ Yet, the role of perivascular PDGFRA-expressing cells and their descendants after tissue injury, such as during osteoarthritis, is not known.

The morphologic features that accompany osteoarthritis after trauma are well catalogued. These features are best described within a rodent model of destabilization of the medial meniscus (DMM) ${ }^{15,16}$ but are broadly applicable to degenerative changes in osteoarthritis in humans. ${ }^{17}$ Of the morphologic features, accumulation of collagenous extracellular matrix and fibrosis of the infrapatellar fat pad (IFP) are common findings. ${ }^{18}$ Diarthrodial joint-associated tissues, such as IFP, house multipotent perivascular cells, ${ }^{19,20}$ presumably which also have a potential for fibrogenesis on injury. However, the role of perivascular FAPs in these histopathologic changes is entirely unknown. Here, we utilized transgenic Pdgfra-CreER ${ }^{\mathrm{T} 2} ; \mathrm{mT} / \mathrm{mG}$ reporter mice for documenting the kinetics and fate of Pdgfra-expressing cells within the knee joint after DMM surgery.

\section{Materials and Methods}

\section{Animals}

All animal studies were performed with the approval of the institutional Animal Care and Use Committee at Johns Hopkins University (Baltimore, MD), and in compliance with all relevant ethics regulations. Pdgfra-CreER ${ }^{\mathrm{T} 2}$ mice were a kind gift from the Bergles Laboratory at Johns Hopkins, commercially available from The Jackson Laboratory (catalog number 018280; Bar Harbor, ME). mT/mG mice were purchased from The Jackson Laboratory (catalog number 007576). Pdgfra-CreER ${ }^{\mathrm{T} 2}$ and $\mathrm{mT} / \mathrm{mG}$ mice were crossed to generate $P d g f r a-\mathrm{CreER}^{\mathrm{T} 2} ; \mathrm{mT} / \mathrm{mG}$ mice, which were used for all experiments. Tamoxifen (TM; product number T5648; Sigma-Aldrich, St. Louis, MO) was provided by i.p. injection as per previously validated protocols to mixed-sex, 7-week-old Pdgfra-CreER ${ }^{\mathrm{T} 2} ; \mathrm{mT} / \mathrm{mG}$ mice for 5 days consecutively $\left(150 \mu \mathrm{g} / \mathrm{g}\right.$ by weight) ${ }^{14}$ With this previously validated TM-injection schedule, $>93.7 \%$ fidelity between reporter activity and immunolocalization was previously observed. ${ }^{21}$ TM was dissolved in sunflower seed oil. Tail genomic DNA was used for genotyping. Essentially no recombination within the joint-associated tissues was observed with the injection of TM-free control vehicle.

\section{Destabilization of the Medial Meniscus}

DMM or sham surgery was performed at the age of 10 weeks, in similarity to prior reports. ${ }^{16}$ Briefly, left hindlimbs were disinfected with povidone-iodine and $70 \%$ ethanol, and suspended-release buprenorphine $(1 \mathrm{mg} / \mathrm{kg})$ was injected s.c. A $1-\mathrm{cm}$ longitudinal incision was made on the medial aspect of the knee joint in mice under general anesthesia, using $2 \%$ isoflurane. Blunt dissection of the joint capsule along the medial side of the patellar ligament was performed to expose the medial meniscotibial ligament. The IFP was exposed, displaced laterally, and the medial meniscotibial ligament was transected using a number 11-blade scalpel to destabilize the medial meniscus. The medial joint capsule and the skin were next closed with 5-0 Prolene suture (Ethicon, Bridgewater, NJ). Sham surgery was performed with a similar surgical approach with visualization, but without transection of the medial meniscotibial ligament. In total, 15 mice were used for histologic examination ( 3 uninjured, 6 at 2 weeks after surgery, and 6 at 8 weeks after surgery), and 6 mice were used for gene expression experiments (3 sham operated, 3 DMM operated).

\section{Micro Computed Tomography}

Knee joints were dissected and imaged with the SkyScan1175 high-resolution micro computed tomography system (Bruker, Billerica, MA) at $65 \mathrm{kV}$ and $153 \mu \mathrm{A}$ with a $1.0-\mathrm{mm}$ aluminum filter to obtain a $10-\mu \mathrm{m}$ voxel size. Images were reconstructed using CT Vox Micro-CT Volume Rendering software version 3.2 (Bruker).

\section{Histologic Examination and Histomorphometry}

Knee joint specimens were fixed in $4 \%$ paraformaldehyde for 24 hours, decalcified with 14\% EDTA for 14 days, and embedded in OCT compound. Sagittal sections of the stifle joint were prepared at $6-\mu \mathrm{m}$ thickness with a Cryofilm type 3c (Section-Lab, Hiroshima, Japan). As a comparison tissue, inguinal fat pads were dissected, embedded in OCT compound (Sakura, Torrance, CA), and cryosectioned at 30- $\mu \mathrm{m}$ thickness. Routine hematoxylin and eosin, Masson's trichrome, Safranin O/Fast Green, and Picro Sirius Red staining were performed, with methods adopted from past work. $^{22-24}$

For immunofluorescence immunohistochemistry analysis, sections were washed in $1 \times$ phosphate-buffered saline, blocked in 5\% normal goat serum (S-1000; Vector Laboratories, Burlingame, CA) for 30 minutes, and incubated with primary antibodies specific for CD31 (1:50; catalog number ab28364), $\alpha$-smooth muscle actin (SMA) (1:400; catalog number ab7817), perilipin (Plin)-1 (1:500; catalog number ab3526), secreted frizzled-related protein (sFRP)-2 (1:100; catalog number ab92667), or macrophage migration inhibitory factor (Mif) (1:100; catalog number ab7207) (all, Abcam, Cambridge, MA) at $4^{\circ} \mathrm{C}$ overnight. Sections were then incubated with Alexa Fluor 647-conjugated secondary antibodies (1:200; catalog number ab150083 or ab150119; Abcam), and mounted with mounting medium containing DAPI (H-1500; Vector Laboratories). Bright field images were obtained on a Leica DM 6B microscope (Leica Biosystems, Wetzlar, Germany) or on a BX43 upright imaging system (Olympus, Tokyo, Japan). Immunofluorescence images were acquired on 
Leica DM 6B and LSM 780 FCS confocal microscopes (Carl Zeiss, Oberkochen, Germany). Tile scans from three to four samples per group were quantified by using ImageJ software version 1.49v (NIH, Bethesda, MD; http://imagej.nih.gov/ij) for reporter activity.

\section{OARSI Scoring of the Knee Joints}

Three frozen semiserial sagittal sections with $36-\mu \mathrm{m}$ intervals were prepared from the medial compartment of each knee joint to represent the weight-bearing area of the distal femur and proximal tibia. ${ }^{25}$ Safranin O/Fast Green-stained sections were analyzed for cartilage injury using the Osteoarthritis Research Society International (OARSI) scoring system. ${ }^{26}$ A range of 0 to 24 was determined according to the following formula: score $=$ grade $(\mathrm{G} 1-\mathrm{G} 6) \times$ stage $(\mathrm{S} 1-\mathrm{S} 4)$. The mean scores from both the femur and the tibia were summed.

\section{Synovial Scoring of the Knee Joints}

Sagittal sections at the level of the posterior cruciate ligament were stained with hematoxylin and eosin. Synovitis was scored using previously published synovitis scoring criteria, ${ }^{27}$ ranging from 0 (minimal inflammation) to 6 (maximal synovitis).

\section{Fibrosis Scoring and Quantification of the Knee Joint}

Masson's trichrome-stained sagittal sections at the level of the posterior cruciate ligament were analyzed for fibrosis of the IFP. Semiquantitative evaluation was performed according to a method previously described. ${ }^{28}$ Briefly, 0 (fibrosis is $<20 \%$ of the total area) indicates normal; 1 ( $20 \%$ to $40 \%$ ) indicates low; 2 (40\% to $60 \%$ ) indicates high; and $3(>60 \%)$ indicates extensive.

\section{Gene Expression Analysis}

To analyze gene expression, IFPs were collected under a dissecting microscope at 2 weeks after sham or DMM surgery $(n=3$ animals per condition). Total RNA was extracted using TRIzol reagent (Thermo Fisher Scientific, Waltham, MA) and the RNeasy Plus mini kit (Qiagen, Germantown, MD). Fifty nanograms of total RNA was used for synthesizing cDNA with the iScript cDNA synthesis kit (Bio-Rad, Philadelphia, PA). Real-time quantitative PCR was performed using QuantStudio 5 (Thermo Fisher Scientific) with PowerUp SYBR Green master mix (Thermo Fisher Scientific). The sequences of the primers used for PCR are shown in Table 1.

\section{Severe Muscle Fibrosis Model and Single-Cell RNA Sequencing}

To identify the genes involved in FAP-mediated fibrosis, a single-cell RNA sequencing data set derived from a rodent model of severe skeletal muscle fibrosis was evaluated. Briefly, fibrosis was induced by a polytrauma, in which an ischemia-generating injury (clamping of the left femoral artery), occluding bloodfor 3 hours (ischemia-reperfusion injury) was combined with an injection of $10 \mu \mathrm{L}$ of cardiotoxin $(3 \mathrm{mg} / \mathrm{mL})$ into the left tibialis anterior, inducing local injury (ischemia-reperfusion injury/cardiotoxin).

Table 1 Real-Time Quantitative RT-PCR Primer Sequences

\begin{tabular}{|c|c|c|}
\hline Gene & Forward & Reverse \\
\hline Acta2 & 5'-AGCCATCTTTCATTGGGATGG-3' & 5'-CCCCTGACAGGACGTTGTTA-3' \\
\hline Ccl2 & $5^{\prime}-\mathrm{TTAAAAACCTGGATCGGAACCAA-3'}$ & 5'-GCATTAGCTTCAGATTTACGGGT-3' \\
\hline Ccl7 & 5'-GTGTCCCTGGGAAGCTGTTA-3' & $5^{\prime}-$ AGAAAGAACAGCGGTGAGGA-3' \\
\hline Cebpa & 5'-GGAACTTGAAGCACAATCGATC-3' & 5'-TGGTTTAGCATAGACGTGCACA-3' \\
\hline Col1a1 & 5'-TGTGTGCGATGACGTGCAAT-3' & 5'-CGGTCCCTCGACTCCTACA-3' \\
\hline Col1a2 & $5^{\prime}-\mathrm{CCAGCGAAGAACTCATACAGC-3^{ \prime }}$ & 5'-GGACACCCCTTCTACGTTGT-3' \\
\hline Col3a1 & $5^{\prime}-$ ACGTAAGCACTGGTGGACAGA-3' & 5'-GAGGGCCATAGCTGAACTGA-3' \\
\hline Col6a1 & 5'-GCTGCTACAAGCCTGCTGGG-3' & 5'-GGCCCCATAAGGTTTCAGCC-3’ \\
\hline $\operatorname{Ctg} f(\operatorname{Con} 2)$ & $5^{\prime}-\mathrm{TCCACCCGAGTTACCAA-3'}$ & $5^{\prime}$-TTAGGTGTCCGGATGC-3' \\
\hline Cxcl1 & 5'-CAAGAACATCCAGAGCTTGAAGGT-3' & 5'-GTGGCTATGACTTCGGTTTGG-3' \\
\hline Eno1 & 5'-AGCGATCCTACTGCCAGAAAT-3' & $5^{\prime}$-GATCGACCTCAACAGTGGGA-3' \\
\hline Gapdh & 5'-GACTTCAACAGCAACTCCCAC-3' & 5'-TCСАCСАСССТGTTGCTG-3' \\
\hline Ier3 & 5'-GAGCGGGCCGTGGTGTC-3' & 5'-сTTGGCAATGTTGGGTTCСтC-3' \\
\hline$M g f p$ & 5'-CAACCACTACCTGAGCACCC-3' & 5'-GTCCATGCCGAGAGTGATCC-3' \\
\hline Mif & 5'-GCCAGAGGGGTTTCTGTCG-3' & 5'-GTTCGTGCCGCTAAAAGTCA-3' \\
\hline Pdgfrb & 5'-AGGACAACCGTACCTTGGGTGACT-3' & 5'-CAGTTCTGACACGTACCGGGTCTC-3' \\
\hline Pparg & 5'-AGGCCGAGAAGGAGAAGCTGTTG-3' & 5'-TGGCCACCTCTTTGCTCTGCTC-3' \\
\hline Ptx3 & 5'-CGCTGTGCTGGAGGAACT-3' & 5'-ATTGCTGTTTCACAACCTGC-3' \\
\hline Serpine1 & 5'-TTCAGCССTTGCTTGCCTC-3' & 5'-ACACTTTTACTCCGAAGTCGGT-3' \\
\hline Sfrp2 & 5'-AGCCTGAGAATCGGCATCTA-3' & 5'-TATTTGAGGGCATCATGCAA-3' \\
\hline Timp1 & $5^{\prime}$-AGCCTCTGTGGATATGCCC-3' & 5'-TCAGAGTACGCCAGGGAACC-3' \\
\hline
\end{tabular}


Baseline uninjured muscle (day 0) and post-trauma tibialis anterior muscles (day 3) were harvested from six ischemiareperfusion injury/cardiotoxin-injured mice and eight uninjured mice. Tibialis anterior muscles were harvested and digested for 20 minutes at $37^{\circ} \mathrm{C}$ under constant agitation with $1640 \mathrm{RPMI}$ media containing $750 \mathrm{U} / \mathrm{mL}$ of type 1 collagenase and $7 \mathrm{U} / \mathrm{mL}$ of Dispase II (Gibco, Gaithersburg, MD). These were quenched with $2 \%$ fetal bovine serum in phosphate-buffered saline and filtered through $40-\mu \mathrm{m}$ sterile strainers. Cells were resuspended at a concentration of $\sim 1000$ cells $/ \mu \mathrm{L}$. Single-cell $3^{\prime}$ library generation was performed on the 10× Genomics Chromium Controller following the manufacturer's protocol for the v2 reagent kit (10x Genomics, Pleasanton, CA). Samples were sequenced using the HiSeq 4000 system (Illumina, San Diego, CA). After sequencing, Cell Ranger Single Cell software suite 1.3 (10x Genomics) was used for performing sample demultiplexing, barcode processing, and single-cell gene counting [alignment, barcoding, and unique molecular identifier (UMI) count] at the University of Michigan Biomedical Core Facilities DNA Sequencing Core (Ann Arbor, MI).

\section{Bioinformatics Analysis of Single-Cell Sequencing Data}

A total of approximately 200 million reads were generated from the 10x Genomics sequencing analysis for each of the replicates (injured, three replicates, two animals each; uninjured, two replicates, four animals each). The sequencing data were first preprocessed using Cell Ranger and aligned to $\mathrm{mm} 10$ genome. For quality control, genes expressed in $<10$ cells, and cells expressing $<500$ genes per cell, or $>20 \%$ mitochondrial UMI content, or UMI content $>60,000$ were filtered out. Replicates from the same group were pooled together for downstream analysis. Downstream analysis steps were performed using the Seurat version 2.3.0 pipeline (Sajita Lab, New York, NY). The downstream analysis steps for each sample type included normalization, scaling, dimensionality reduction (principal component analysis and t-distributed stochastic neighbor embedding), unsupervised clustering, cluster consolidation via centroid rank correlation analysis, and discovery of differentially expressed cluster-specific markers. The presence of replicate batch effect was ruled out by visual inspection of the contribution of each replicate to the principal component analysis and t-distributed stochastic neighbor embedding projections of the group. The clustering procedure followed two steps. Provisional clusters were assigned via unsupervised clustering (Seurat FindClusters; Louvain algorithm, $\mathrm{k}=30$, resolution $=0.4$ ). This procedure led to eight provisional clusters in the injured group, and nine provisional clusters in the uninjured group. Provisional clusters were aligned according to the rank correlation of their centroids, measured on the gene set derived from the intersection of the genes for each set (12,619 genes). Consolidated clusters were obtained by aggregating similar clusters based on centroid rank correlation analysis, and their cell type was labeled according to their distinguishing markers. Pdgfra ${ }^{+}$FAPs were selected from both groups, and their gene expression levels were compared for the finding of distinguishing markers.

\section{Statistical Analysis}

One-way analysis of variance tests followed by TukeyKramer tests were used for analysis of the results of each evaluation, except for gene expression results. The Dunnett test was used for analysis of gene expression results. All statistical analyses were performed using Prism software version 8 (GraphPad Software, San Diego, CA) and JMP software version 13 (SAS Institute Inc., Cary, NC). $P<0.05$ was considered statistically significant.

\section{Results}

Pdgfra Reporter Activity and Perivascular Cells within the Infrapatellar Fat Pad

The distribution of $P d g f r a$-expressing cells was first examined within the IFP using $P d g f r a-C_{r e E R}{ }^{\mathrm{T} 2} ; \mathrm{mT} / \mathrm{mG}$ reporter animals (Figure 1). For comparison, s.c. fat was also examined, which was previously described to contain two perivascular domains of Pdgfra reporter activity. ${ }^{14}$ For this experiment, TM was administered to Pdgfra-CreER ${ }^{\mathrm{T} 2} ; \mathrm{mT} /$ $\mathrm{mG}$ transgenic mice for 5 consecutive days at 7 weeks of age (Figure 1A). First, it was confirmed that s.c. (inguinal) fat demonstrated perivascular Pdgfra reporter activity (Figure 1, B-D), primarily within the tunica adventitia of larger blood vessels (Figure 1C). A second, and more restricted, domain of perivascular Pdgfra reporter activity was also observed within a pericytic location in the tunica intima (Figure 1D). Similar perivascular distributions of Pdgfra reporter activity were found within the IFP of the knee joint (Figure 1, E-G). Here, Pdgfra reporter was again most common in the tunica adventitia of larger microvessels (Figure 1F), while some cells within a pericytic location also demonstrated reporter activity (Figure 1G). Thus, Pdgfra reporter activity within intracapsular fat pads demonstrates perivascular domains similar to those of s.c. fat. ${ }^{14}$

\section{Confirmation of Osteoarthritic Changes after Joint Destabilization among Pdgfra Reporter Animals}

Pdgfra reporter animals underwent degenerative changes after DMM surgery, as expected (Figure 2). In these experiments, TM was administered to $P d g f r a-\mathrm{CreER}^{\mathrm{T} 2} ; \mathrm{mT} /$ $\mathrm{mG}$ transgenic mice for 5 consecutive days at 7 weeks of age; mice were subjected to DMM or sham surgery at 10 weeks of age and analyzed at 2 and 8 weeks thereafter (Figure 2A). An uninjured group was also made to examine the baseline joint state at 10 weeks of age. Micro computed tomography of the left knee joint confirmed 


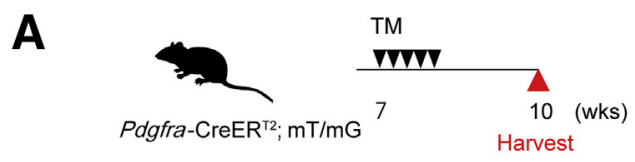

s.c. fat
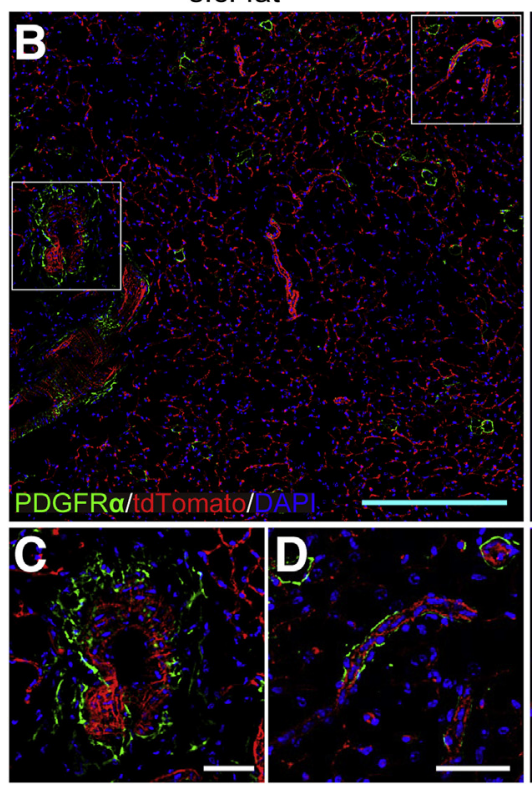

Pericytic

Adventitia

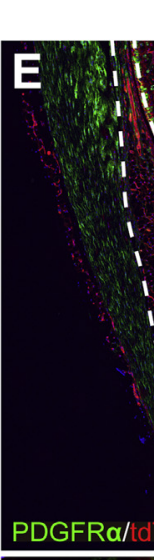

Knee joint

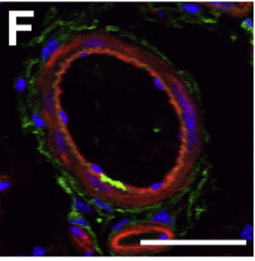

Adventitia

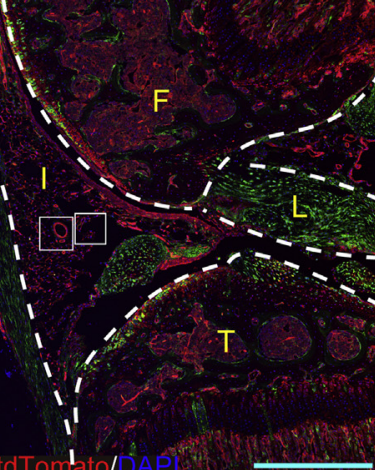

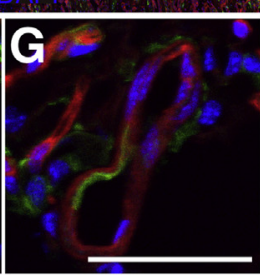

Figure 1 Pdgfra-CreER ${ }^{\top 2}$ reporter animals highlight perivascular cell populations in both s.c. and infrapatellar fat pads (IFPs). A: Schematic of experiments, including tamoxifen (TM) injection daily to Pdgfra-CreER ${ }^{\mathrm{T} 2} ; \mathrm{mT} / \mathrm{mG}$ mice for 5 consecutive days at 7 weeks of age, followed by harvesting s.c. (inguinal) white adipose tissue and knee joint at 10 weeks of age. B-D: Perivascular Pdgfra reporter activity within the s.c. (inguinal) white adipose niche, including representative tile scan image (B), with boxed regions corresponding to higher magnifications within the tunica adventitia $(\mathbf{C})$ and less frequent reporter activity within a pericytic location (D). E-G: In comparison, perivascular Pdgfra reporter activity within the IFP, including representative tile scan (E), with boxed regions corresponding to higher magnifications of perivascular cells within the tunica adventitia (F) and less frequent reporter-positive pericytes $(\mathbf{G})$. The dashed lines represent the boundaries of different tissue areas. $n=3$ mice analyzed per tissue depot. Scale bars: $250 \mu \mathrm{m}$ (B and $\mathbf{E})$; $50 \mu \mathrm{m}(\mathbf{C}, \mathbf{D}, \mathbf{F}$, and G). F, femur; I, infrapatellar fat pad; L, posterior cruciate ligament; $\mathrm{T}$, tibia. destabilization of the medial meniscus among the DMM treatment groups at 2 and 8 weeks after surgery (Figure 2B). Sagittal histologic sections of the joint were next stained with Safranin O/Fast Green (Figure 2, C and D). Results confirmed a significant and progressive degeneration of the anterior horn of the medial meniscus (Figure 2C) and loss of Safranin O staining among DMM animals (Figure 2D), but not sham-operated or uninjured animals (Figure 2, C and D). These findings were most notable within the proximal tibial articular cartilage, but were also evident within the distal femoral cartilage. Degenerative changes were further confirmed using the OARSI scoring system, which showed a progressive increase in scores across 2 and 8 weeks among DMMtreated animals (mean OARSI scores, 4.8 and 11.1 at 2 and 8 weeks after DMM, respectively) (Figure 2E).

\section{Synovitis and Subsynovial Fibrosis after Joint Destabilization}

Having confirmed osteoarthritic changes after DMM, this study next examined in detail the histologic changes within IFP after either sham or DMM surgery. For this purpose, sagittal sections of the knee joint were obtained at the level of the posterior cruciate ligament (Figure 3) and stained with hematoxylin and eosin (Figure 3, A and B), Masson's trichrome (Figure 3C), and Picro Sirius Red (Figure 3D).
Results showed marked fibrosis within the IFP as early as 2 weeks after DMM (Figure 3, C and D). In comparison, little histologic change within the IFP was observed in shamoperated animals. Inflammatory changes within the IFP and overlying synovium were next quantified using a semiquantitative scoring system (Figure 3E). Synovitis score was highest at 2 weeks after DMM and remained elevated at 8 weeks after DMM (mean synovitis scores, 5.0 and 4.3 at 2 and 8 weeks after DMM, respectively). Next, fibrosis was scored to quantify the qualitative impression of increased IFP fibrosis after joint destabilization (Figure 3F). Fibrosis score was significantly elevated among the DMMtreated groups only, observed at both 2 and 8 weeks after surgery (mean fibrosis scores, 2.7 and 2.0 at 2 and 8 weeks after DMM, respectively).

\section{Pdgfra Lineage Tracing after Joint Destabilization}

The fibrotic changes within the IFP elicited by joint destabilization were confirmed and the Pdgfra reporter activity was examined using inducible $P d g f r a-\mathrm{CreER}^{\mathrm{T} 2} ; \mathrm{mT} / \mathrm{mG}$ transgenic animals (Figure 4A). For this purpose, the IFP was separated for analysis into histologically distinct areas as previously described, ${ }^{28}$ either with more predominantly adipose tissue within the proximal IFP (Figure 4B) or more vasculature within the distal IFP (Figure 4C). In the uninjured condition, perivascular Pdgfra reporter activity was 
again observed in both small and medium vessels. These findings were essentially confirmed among the IFPs of sham-operated animals at both 2 and 8 weeks after surgery. In contrast, the domain of Pdgfra reporter activity was significantly broadened after joint destabilization. DMM induced a marked expansion in the numbers and distribution of membrane-bound green fluorescent protein (mGFP)/ Pdgfra-expressing cellular descendants. Within DMMtreated joints, confluent reporter-positive cells were observed, while most of the reporter-negative cells [tandem dimer (td)Tomato ${ }^{+}$cells] appeared to be endothelium of blood vessels. Quantification of reporter activity confirmed this impression (Figure 4D), with mGFP-expressing cells significantly increased among DMM-treated joints, especially at 8 weeks after injury.

\section{Immunophenotype of Pdgfra-Expressing Cells after Joint Destabilization}

To further typify Pdgfra-expressing cells with or without joint destabilization, immunohistochemistry staining was next performed on Pdgfra reporter sections (Figure 5 and
Supplemental Figure S1). First, it was confirmed that $\mathrm{Pdgfra}^{+}$cells were not endothelial, by immunohistochemistry staining for CD31 (Figure 5, A-D, and Supplemental Figure S1A). Consistent with prior observations in s.c. fat, ${ }^{14}$ Pdgfra reporter activity did not co-localize with CD31 immunostaining. This finding was observed across all time points, and in both sham-operated and DMM-operated animals.

It was next examined whether Pdgfra reporter cells within the IFP acquired a fibrogenic or adipogenic cell fate after DMM. For this purpose, immunohistochemistry staining was performed for the fibroblast/myofibroblast marker $\alpha$-SMA (Figure 5, E-H, and Supplemental Figure S1B) as well as the adipocyte marker Plin1 (Supplemental Figure S2). In uninjured and sham-operated controls, $\alpha$-SMA staining was primarily confined to vessel walls within the IFP and showed rare overlap with Pdgfra reporter activity (Figure 5, E and F). In contrast, $\alpha$-SMA staining was broadly expanded in the injured (DMM-operated) fat pad, with numerous dual $\mathrm{mGFP}^{+} \alpha-\mathrm{SMA}^{+}$cells (Figure 5, G and H). Dual-positive cells were most conspicuous at 2 weeks after DMM, but persistent at 8 weeks

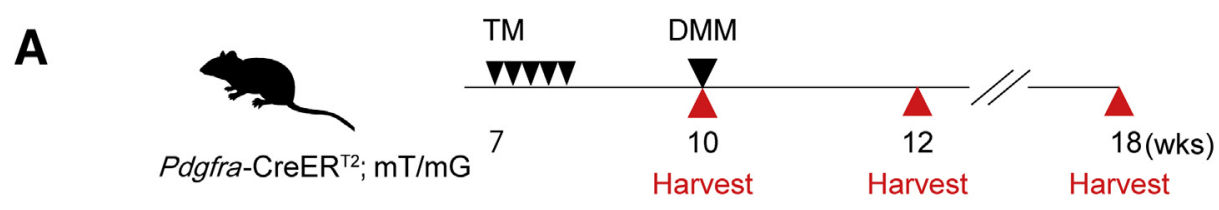

Uninjured
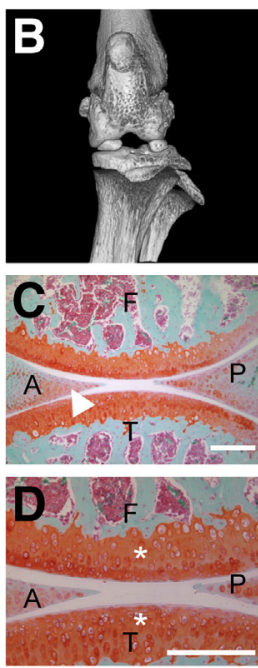

Sham 2wks
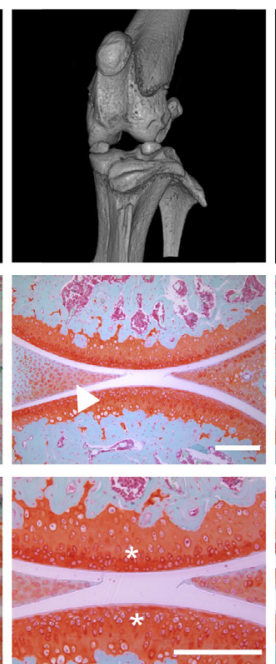

DMM 2wks
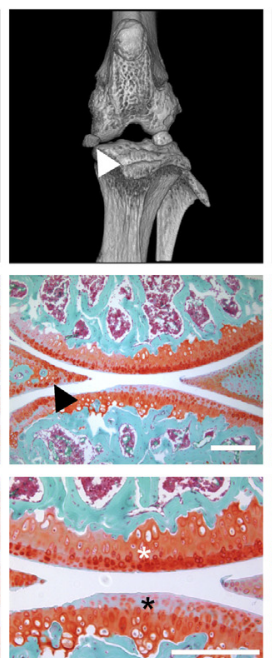

Sham 8 wks
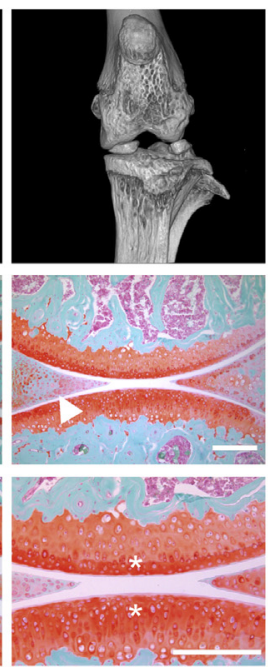

DMM 8wks
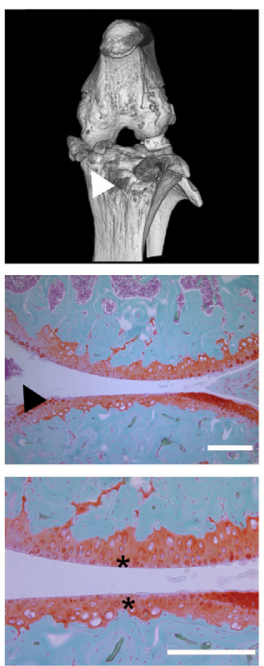

E

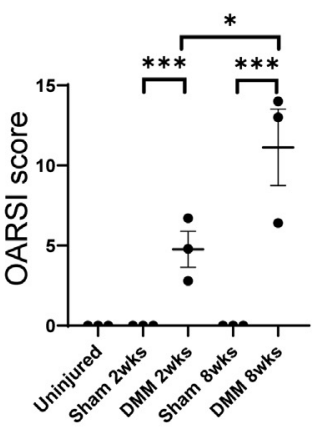

Figure 2 Validation of osteoarthritis after destabilization within Pdgfra-CreER ${ }^{T 2}$ reporter animals. A: Schematic of experiments, including tamoxifen (TM) injection daily to $P d g f r a-C r e E R^{T 2} ; \mathrm{mT} / \mathrm{mG}$ mice for 5 consecutive days at 7 weeks of age, followed by destabilization of the medial meniscus (DMM) surgery at 10 weeks of age. Analyses were performed at 2 and 8 weeks after sham or DMM, with comparisons to uninjured animals. B: Micro computed tomography reconstructions of the left knee joints of $P d g f r a-C r e E R^{T 2} ; \mathrm{mT} / \mathrm{mG}$ mice. Arrowheads indicate the displaced medial meniscus at 2 and 8 weeks after surgery among DMM groups. C: Safranin 0/Fast Green-stained sagittal sections of the left knee joints at the level of the medial compartments. Changes to the anterior horns of the medial meniscus after DMM are indicated with black arrowheads in comparison to controls (white arrowheads). D: High magnifications of Safranin 0/ Fast Green-stained sections. Changes to the articular cartilage are marked with black asterisks in comparison to controls (white asterisks). E: 0steoarthritis Research Society International (OARSI) scores at 2 and 8 weeks after sham or DMM surgery within Pdgfra-CreER ${ }^{\mathrm{T2}}$ reporter mice, in relation to uninjured control. Data are expressed as means $\pm 1 \mathrm{SEM}$, with dots representing data from individual animals. $n=3$ animals per timepoint per condition. ${ }^{\star} P<0.05$, ${ }^{* * *} P<0.001$. A, anterior horn of the medial meniscus; F, femur; $\mathrm{P}$, posterior horn of the medial meniscus; $\mathrm{T}$, tibia. Scale bars $=100 \mu \mathrm{m}$. 
Uninjured
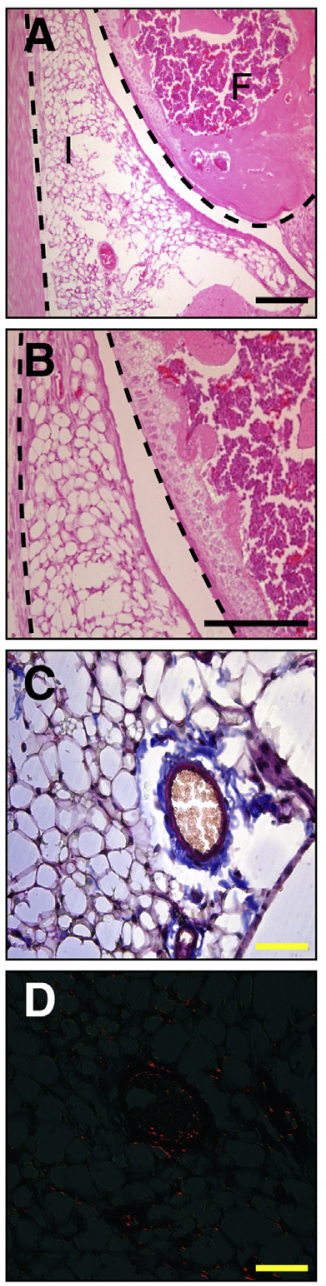

$\mathbf{E}$
Sham 2wks
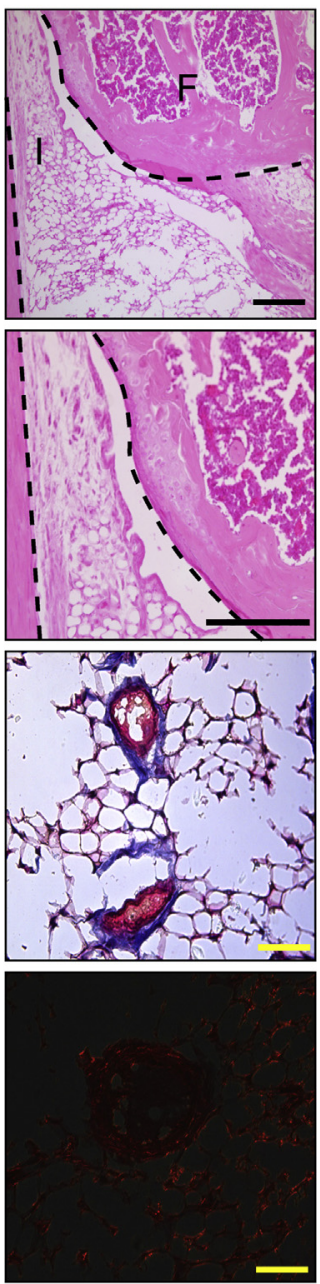

$\mathbf{F}$
DMM 2wks
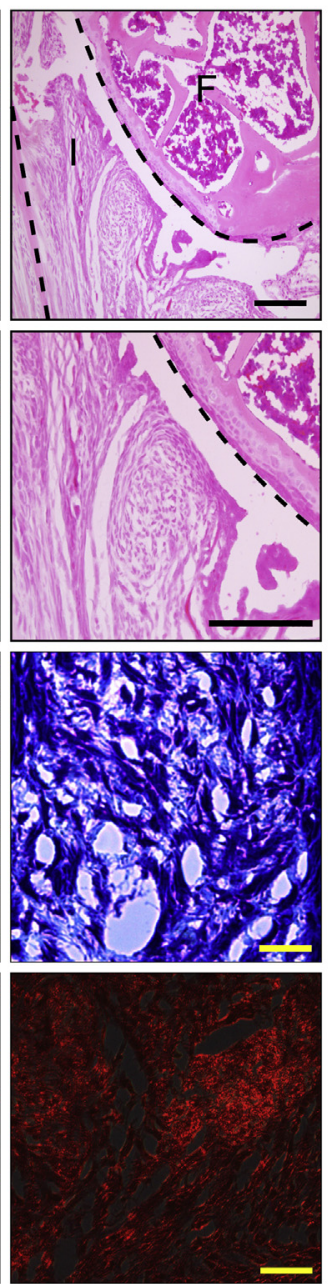

Sham 8wks
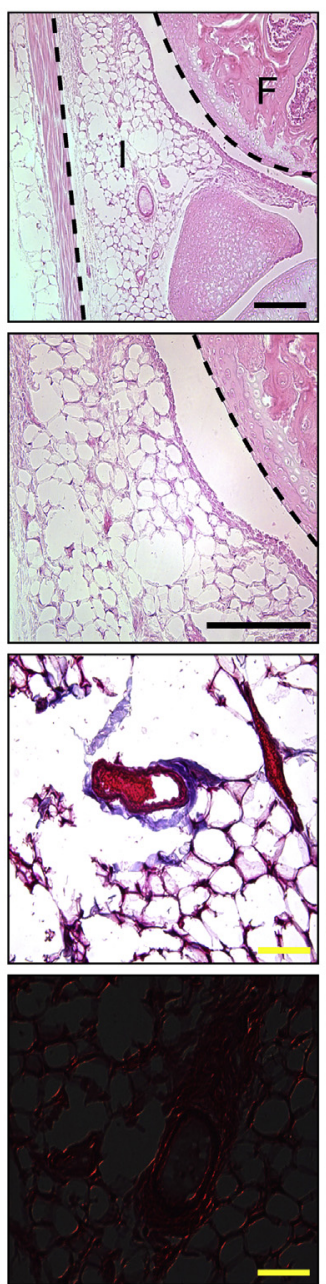

DMM 8wks
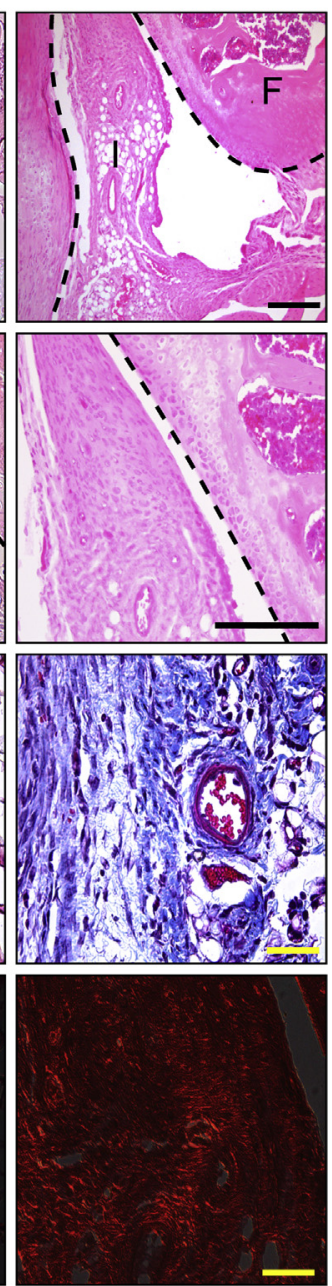
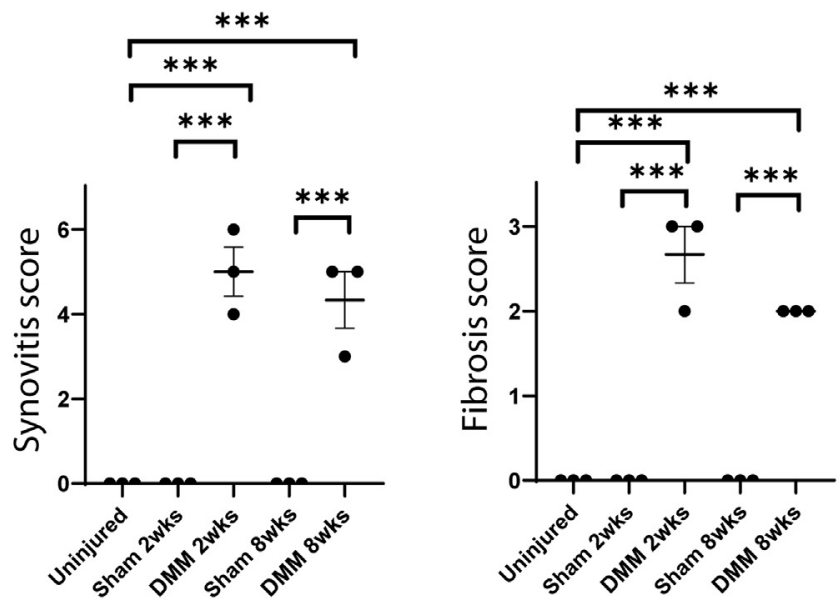

Figure 3 Infrapatellar fat pad (IFP) fibrosis elicited by joint destabilization in Pdgfra-CreER ${ }^{T 2}$ reporter animals. Sagittal sections of the left stifle joints of $P d g f r a-C r e E R^{\top 2} ; m T / m G$ animals at the level of posterior cruciate ligaments. A and B: Hematoxylin and eosin staining at low (A) and high (B) magnifications. Dashed lines represent the boundary of different tissue areas. C: Masson's trichrome staining of the IFP, with collagenous tissue appearing blue. D: Picrosirius red staining of the IFP, with collagenous tissue appearing red under polarized light. $\mathbf{E}$ and $\mathbf{F}$ : Synovitis (E) and fibrosis (F) scoring at 2 or 8 weeks after sham or destabilization of the medial meniscus (DMM) surgery within Pdgfra$\mathrm{CreER}^{\mathrm{T2}}$ reporter mice, in relation to uninjured control. Data are expressed as means \pm 1 SEM, with dots representing data from individual animals. $n=3$ animals per timepoint per condition. ${ }^{* * *} P<0.001$. Scale bars: $100 \mu \mathrm{m}$ (A and B); $50 \mu \mathrm{m}$ (C and D). F, femur; I, infrapatellar fat pad.

after injury (Supplemental Figure S1B). Next, an adipocytic cell fate was assayed by immunostaining for Plin1 (Supplemental Figure S2). As expected, Plin $1^{+}$adipocytes were numerous in the uninjured IFP as well as within the sham-operated controls, most of which were tdTomato ${ }^{+}$ rather than $\mathrm{mGFP}^{+}$(Supplemental Figure S2, A-D, G, and H). In the DMM treatment condition, domains of Pdgfra reporter cell expression were largely distinct from Plin1 
expression (Supplemental Figure S2, E, F, I, and J), while in some instances $\mathrm{mGFP}^{+}$cells appeared adjacent to, but nonoverlapping with, Plin $1^{+}$adipocytes (Supplemental Figure S2, E and F). Thus, in the context of joint destabilization, Pdgfra-expressing cells and descendants thereof adopt myofibroblast but not endothelial or adipocyte immunophenotypes within the IFP.

\section{Gene Markers of Fibrosis and Injured FAPs after Joint Destabilization}

Expansion of $P d g f \mathrm{ra}^{+} \alpha-\mathrm{SMA}^{+}$accompanying subsynovial fibrosis was highly suggestive of perivascular-tomyofibroblast transition induced by joint destabilization. To further investigate, IFPs from DMM- or sham-operated animals were microdissected and pooled for quantitative real-time PCR analysis, performed at 2 weeks after injury (Figure 6). Confirming the histologic observations, mGFP transcripts reflecting Pdgfra reporter activity were increased 7.40-fold after DMM in comparison to control $(P<0.001)$ (Figure 6A). Pdgfrb, which marks pericytes and a subset of $P d g$ fra-expressing perivascular cells, ${ }^{29}$ was also increased but to a lesser degree (4.15-fold change, $P<0.01)$. Additional genes markers of fibrosis were examined among microdissected IFPs. ${ }^{30}$ Briefly, a 3.37fold change in Acta 2 was observed (encoding $\alpha$-SMA), as well as a 43.4- to 198-fold change in genes encoding collagens associated with fibrotic repair (Collal, Colla2, Col3al, and Col6al). In addition, a 235-fold change in connective tissue growth factor $(\mathrm{Ctg} f)$ expression and a 14.9-fold change in tissue inhibitor of metalloproteinase 1 (Timp1) were observed (Figure 6B). In contrast, gene markers associated with adipogenic differentiation were not significantly upregulated after DMM, including the transcription factors Pparg and Cebpa (Supplemental Figure S2K).
Uninjured
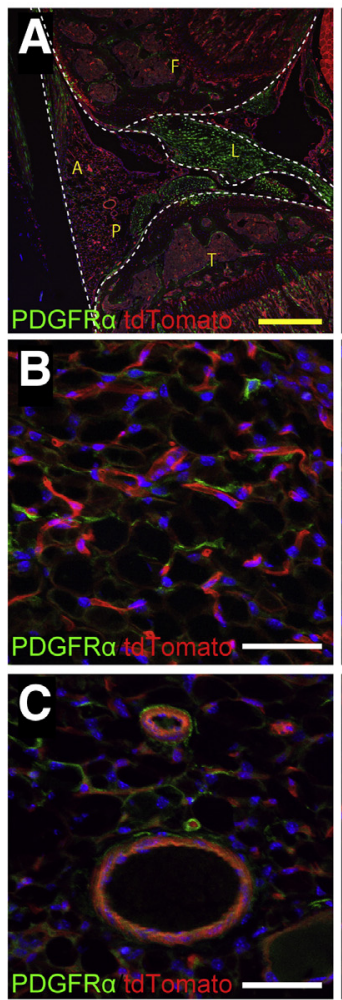

D

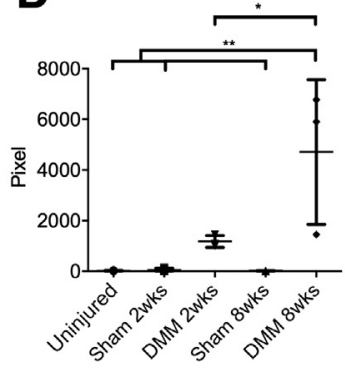

Sham 2wks
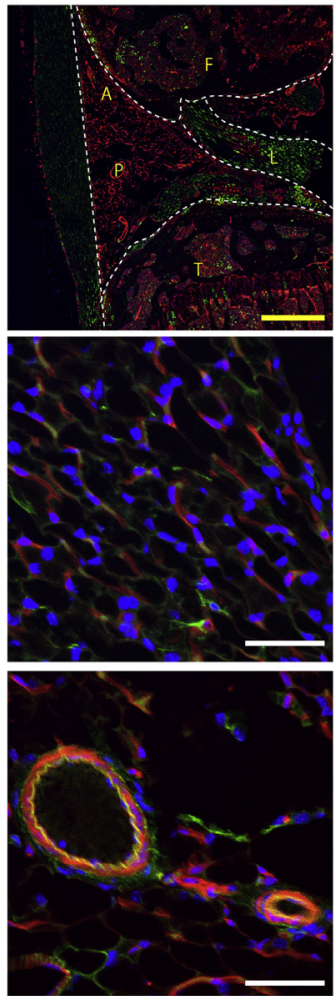

DMM 2wks
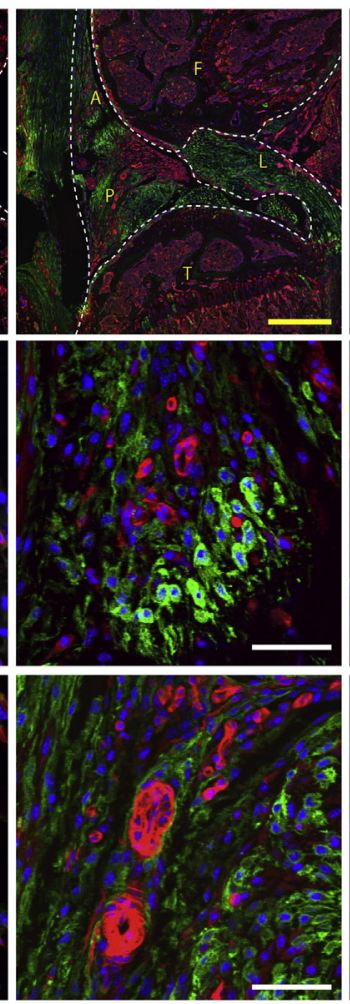

Sham 8wks
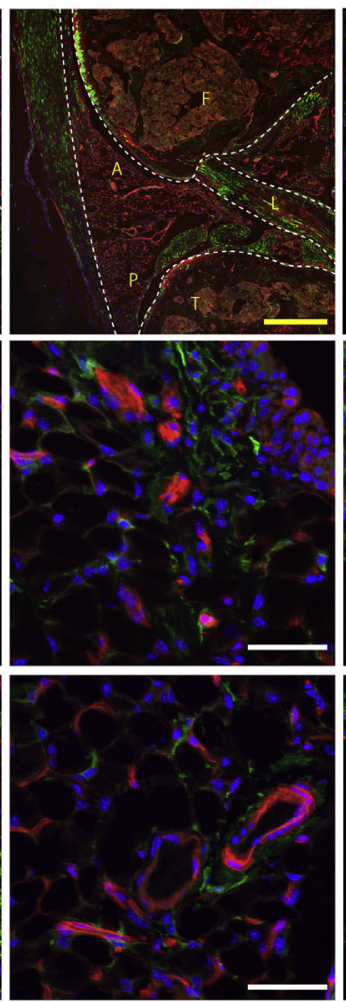

DMM 8wks
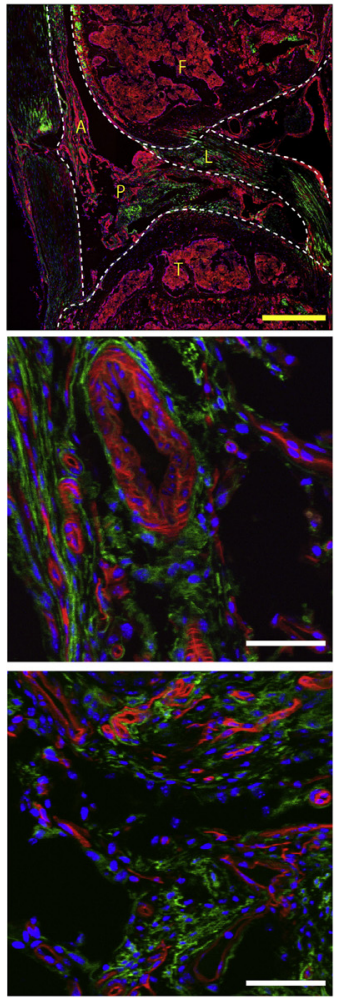

Figure 4 Expansion of perivascular Pdgfra-expressing cellular descendants after joint destabilization. A: Low magnification immunofluorescence images of the knee joints among $P d g f r a-C r e E R^{\top 2}$ reporter mice. Sagittal sections are shown at the level of posterior cruciate ligaments. Pdgfra reporter activity appears green, while all other cells appear red. DAPI nuclear counterstain appears blue. Dashed lines represent the boundary of different tissue areas. B and C: High magnifications of $P d g f r a-C r e E R^{T 2}$ reporter activity within either adipose (B) or perivascular (C) areas. D: Quantification of $P d g f r a$ reporter activity in each group. Data are expressed as means \pm 1 SEM, with dots representing data from individual animals. $n=3$ animals per timepoint per condition. ${ }^{*} P<0.05,{ }^{*} P<0.01$. Scale bars: $200 \mu \mathrm{m}(\mathbf{A}) ; 50 \mu \mathrm{m}$ (B and C). $A$, adipose area; DMM, destabilization of the medial meniscus; $F$, femur; $L$, posterior cruciate ligament; $P$, perivascular area; T, tibia. 
Having confirmed that Pdgfra-expressing perivascular cells expand after joint destabilization and adopt a geneexpression profile consistent with fibrotic repair, it was next examined how this may be transcriptionally similar or distinct from other examples of Pdgfra-expressing FAPmediated fibrosis. For this purpose, we utilized our previously constructed single-cell RNA sequencing data set (http://www.ncbi.nlm.nih.gov/geo; accession number GSE144270) produced from fibrotic mouse muscle induced by intramuscular cardiotoxin and ischemia to induce severe muscle fibrosis (Supplemental Figure S3) ${ }^{31}$ Unsupervised cell clustering identified eight and nine cell clusters in uninjured and injured muscle, respectively (Supplemental Figure S3, A and B), ${ }^{31}$ including one population in each data set representing Pdgfra-expressing FAPs (Supplemental Figure S3, C and D), which also expressed characteristic markers such as paired related homeobox 1 (Prrxl) and collagen type $1 \alpha_{1}$ chain (Collal). FAPs represented $13.7 \%$ of cells within uninjured muscle (2760 total cells) and $14.4 \%$ after injury (7718 total cells). To determine the transcriptional profile of FAPs during fibrotic repair, differentially expressed genes among injured versus uninjured FAPs were next assessed (Supplemental Figure S3E). The 10 highest differentially expressed genes in injured skeletal muscle FAPs were identified, and included chemokines and inflammatory regulatory factors such as $\mathrm{C}-\mathrm{C}$ motif chemokine ligands 2 and 7 ( $\mathrm{Ccl} 2$ and Ccl7), C-X-C motif chemokine ligand 1 ( $\mathrm{Cxcll})$, pentraxin 3 (Ptx3), Mif, inhibitor of metalloproteinases such as Timp1, fibrinolysis-related genes including serpin family $\mathrm{E}$ member 1 (Serpinel) and enolase 1 (Enol), the Wnt-signaling inhibitor Sfrp2, and the apoptosis-related gene immediate early response 3 (Ier3). Next, these 10 differentially expressed genes were again assayed in microdissected IFPs after DMM (Figure 6B). Five of ten differentially expressed genes-Ccl7, Mif, Timp1, Enol, and Sfrp2-showed significant up-regulation (2.64- to 14.9-fold changes) in both models (Figure 6C). Immunofluorescence images of Sfrp2 and Mif also confirmed increased expression of these two markers after DMM, especially in and around areas of Pdgfra-expressing cells (Supplemental Figure S4). In contrast, Ccl2, Cxcl1, Ptx3, Serpine1, and Ier3 showed no significant change with or without DMM. Thus, gene expression within FAPs in chemically and ischemically injured skeletal muscle overlaps with that observed in injury induced by joint destabilization. Common markers among both processes included genes associated with immune regulation, fibrosis, and fibrinolysis.

\section{Discussion}

In the present study, we observed that joint destabilization induces dynamic changes in Pdgfra-expressing perivascular
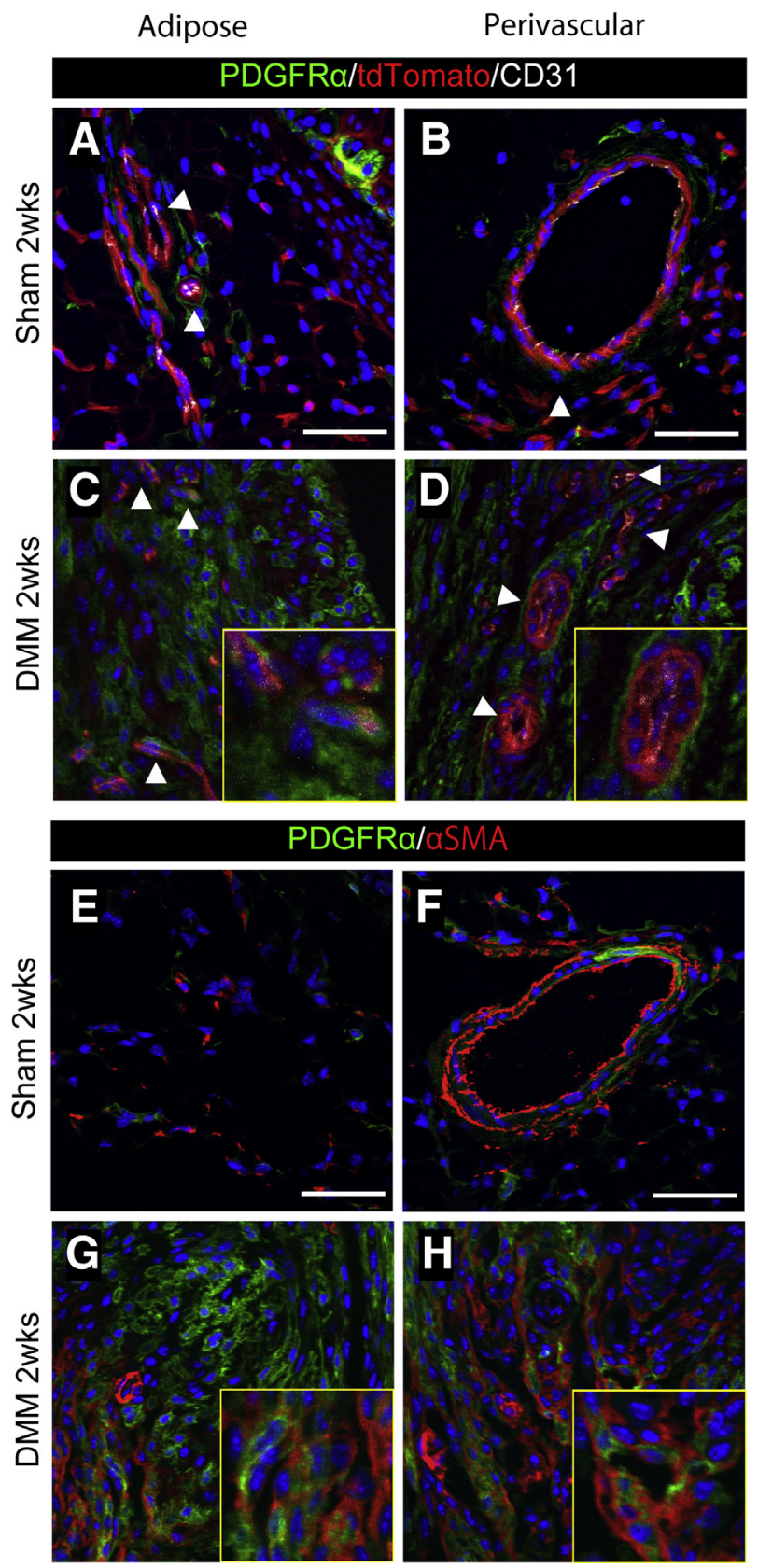

Figure 5 Immunophenotypic characterization of Pdgfra-expressing cells after joint destabilization. A-D: High-magnification images of CD31 immunofluorescence staining in combination with Pdgfra-CreER ${ }^{T 2}$ reporter activity within infrapatellar fat pad (IFP) in sham or destabilization of the medial meniscus (DMM) surgery. Pdgfra reporter activity appears green, while other cells appear red, CD31 immunostaining appears white. Arrowheads indicate vessels. Corresponding images at other timepoints are shown in Supplemental Figure S1A. E-H: High-magnification images of $\alpha$-smooth muscle actin immunofluorescence staining in combination with Pdgfra-CreER ${ }^{\top 2}$ reporter activity within IFP in sham or DMM surgery. Pdgfra reporter activity appears green, while $\alpha$-SMA immunostaining appears red. DAPI nuclear counterstain appears blue in all the panels. High-magnification images are shown in insets. Corresponding images at other timepoints are shown in Supplemental Figure S1B. $n=3$ animals per timepoint per condition. Scale bars $=50$ $\mu \mathrm{m}$. Original magnification, $\times 40$ (insets). 

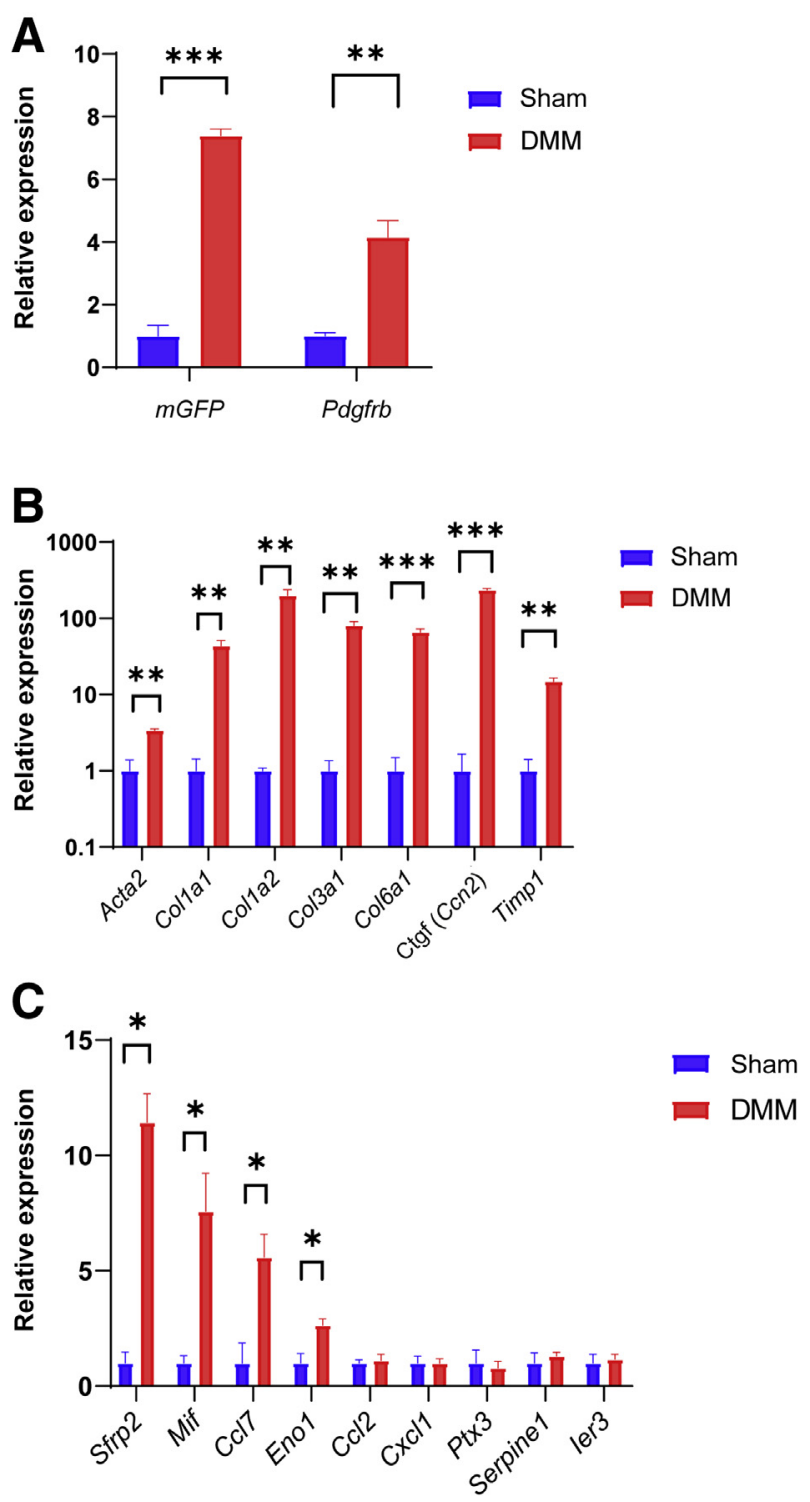

Figure 6 Gene markers of fibrosis and fibro-adipogenic progenitors (FAPs) after joint destabilization. A: Membrane-bound green fluorescent protein (mGFP) (Pdgfra) reporter activity and Pdgfrb expression within the microdissected infrapatellar fat pad (IFP) of Pdgfra reporter animals, assessed by real-time quantitative RT-PCR (RT-qPCR) at 2 weeks after sham or destabilization of the medial meniscus (DMM) surgery. B: Gene markers associated with fibrosis within the microdissected IFP of Pdgfra reporter animals, assessed by RT-qPCR at 2 weeks after sham or DMM surgery. C: Quantification of top 10 differentially expressed genes of injured FAPs within the microdissected IFP of Pdgfra reporter animals, assessed by RT-qPCR at 2 weeks after sham or DMM surgery. Timp1 was previously assayed and is shown in Figure $6 \mathrm{~B}$. Data are expressed as normalized means \pm 1 SEM of gene expression. $n=3$ mice per group. ${ }^{*} P<0.05,{ }^{*} P<0.01$, and $* * * P<0.001$

cells and their descendants within the IFP. Expansion of perivascular Pdgfra-expressing cells was observed, accompanied by perivascular-to-myofibroblastic cell transition, fat pad fibrosis, and a gene signature that corresponds to fibrosis and injury-associated FAPs.
Other models of experimental osteoarthritis likewise have IFP fibrosis as a histologic component. For example, a prior study observed that cyclic tibial compression of articular cartilage was associated with IFP fibrosis. ${ }^{32}$ Likewise, in another study in high-fat diet-associated osteoarthritis, IFP fibrosis was observed, including increased expression of genes associated with fibrosis and extracellular matrix production. ${ }^{33}$ These noninvasive experimental findings suggest that some degree of IFP fibrosis is a conserved feature of experimental murine models of osteoarthritis. The extent to which fibrosis in IFP faithfully mirrors the pathology of osteoarthritis in humans is yet unclear.

Our findings within the IFP elicited by joint destabilization are analogous to findings on tissue-repair processes in other organs. For instance, subpopulations of perivascular cells have also been reported to contribute to fibrosis in a context-dependent manner. After injury, perivascular mesenchymal stem/stromal cells progenitors may drive the crucial remodeling of the affected organ, reducing its function dramatically. Resident $\mathrm{GLII}^{+}$perivascular cells have been reported to produce myofibroblasts on renal, pulmonary, hepatic, or cardiac injury, contributing to organ failure, which was rescuable on ablation of these cells. ${ }^{4}$ $\mathrm{GLII}^{+}$progenitors also have been reported to contribute to calcification of vessels, ${ }^{34}$ and to be pharmacologically targetable with the GLI family zinc finger 1 (GLI1) inhibitor GANT61 for the prevention of fibrosis in the bone marrow. ${ }^{35}$ Similarly, $\alpha \mathrm{v}$ integrins on perivascular and interstitial cells in skeletal and cardiac muscles have been reported to contribute to fibrosis by transforming growth factor (TGF)- $\beta$ signaling after injury. ${ }^{9}$ Fibrosis by TGF- $\beta$ signaling after injury can be genetically controlled by $\alpha \mathrm{v}$ integrin ablation, or pharmacologically alleviated by targeting $\alpha v$ integrins. Indeed, two signaling pathways are most well studied in modulating platelet-derived growth factor receptor (PDGFR)- $\alpha$-expressing FAPs during fibrosis, including TGF- $\beta$ and PDGF signaling. TGF- $\beta$ is a well-documented profibrotic factor. ${ }^{36-39}$ In fact, all three TGF- $\beta$ isoforms have been shown to stimulate FAP proliferation and extracellular matrix production. ${ }^{40}$ TGF- $\beta$ noncanonical pathways have also been reported to be involved in myofibroblast activation and fibrogenesis. ${ }^{40-42}$ In addition, PDGF ligands have been shown to signal through PDGFR- $\alpha$ to regulate the proliferation and differentiation of FAPs $^{33,42,43}$ and to cause tissue fibrosis via up-regulation of mammalian target of rapamycin signaling and ribosome biogenesis pathways. ${ }^{44}$ Although at this point theoretical, the experimental targeting of FAPs may also alter intracapsular fibrosis after joint destabilization.

Recent research has made clear the diversity of mesenchymal cell types within the perivascular niche and revealed an increasingly complex phenotypic and functional heterogeneity of perivascular cells. For example, a developmental hierarchy of pericytes and other perivascular cells has been established by single-cell transcriptome analysis within fat tissue in humans. ${ }^{45}$ Correlatively, it was recently observed 
that subsets of perivascular adventitial cells in vessels in

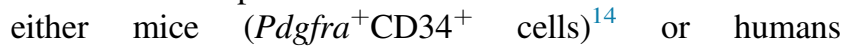
$\left(\mathrm{CD} 34^{+} \mathrm{CD} 10^{+} \text {cells }\right)^{46}$ have a greater capacity to proliferate and mineralize. As the functional heterogeneity of perivascular cells that participate in tissue repair is uncovered, it stands to reason that their differential roles in tissue fibrosis may also be revealed. For example and in work already performed using distinct transgenic models, a subset of $P d g f r b^{+}$perivascular cells co-expressing Pdgfra demonstrated fibrotic repair and contributed to fatty degeneration after massive tear of the rotator cuff in mice. ${ }^{29}$

Compounding the tissue-intrinsic diversity of perivascular cells, multiple observations have suggested that perivascular cell types have tissue-specific functions. For example, perivascular stem cells obtained from the IFP in humans have been reported to be more apt to undergo chondrogenic differentiation. ${ }^{19,20}$ In another example, CD146 ${ }^{+}$pericytes from intramuscular depots in humans have been reported to be more apt to undergo myogenesis in vitro and in vivo. ${ }^{18}$ Indeed, in the present study, we identified that Pdgfraexpressing cells within injured skeletal muscle had a transcriptional network that overlapped, but was distinct from, that of cells within the IFP, as only $50 \%$ of genes up-regulated in skeletal muscle fibrosis showed a significant increase within IFP fibrosis. In past observations in mice, perivascular Pdgfra reporter activity was a common finding across all tissues analyzed, ${ }^{14}$ although the relative frequency differed from organ to organ. It is intriguing, however speculative, to wonder whether perivascular Pdgfra-expressing cells have similar fibrogenic potentials across tissues.

In summary, transgenic inducible Pdgfra reporter animals highlight perivascular cell populations within the intracapsular fat pad, and represent a means of tracking cell fate after surgical destabilization of the joint. Here, joint destabilization resulted in proliferation of perivascular Pdgfraexpressing cells, accompanied by perivascular to myofibroblastic cell transition, fat pad fibrosis, and a gene signature that corresponded to fibrotic repair. Among future questions for investigation, it is currently unknown as to whether Pdgfra-expressing cellular descendants play paracrine roles that contribute to cartilage degeneration after destabilization. In addition, it is currently unknown whether an analogous cellular process occurs in inflammatory arthritis, or whether this is confined to trauma-associated osteoarthritis.

\section{Supplemental Data}

Supplemental material for this article can be found at https://doi.org/10.1016/j.ajpath.2020.05.017.

\section{References}

1. Lindblom $\mathrm{P}$, Gerhardt $\mathrm{H}$, Liebner $\mathrm{S}$, Abramsson A, Enge $\mathrm{M}$, Hellstrom M, Backstrom G, Fredriksson S, Landegren U, Nystrom HC, Bergstrom G, Dejana E, Ostman A, Lindahl P,
Betsholtz C: Endothelial PDGF-B retention is required for proper investment of pericytes in the microvessel wall. Genes Dev 2003, 17: $1835-1840$

2. Volz KS, Jacobs AH, Chen HI, Poduri A, McKay AS, Riordan DP, Kofler N, Kitajewski J, Weissman I, Red-Horse K: Pericytes are progenitors for coronary artery smooth muscle. Elife 2015, 4:e10036

3. Crisan M, Yap S, Casteilla L, Chen CW, Corselli M, Park TS, Andriolo G, Sun B, Zheng B, Zhang L, Norotte C, Teng PN, Traas J, Schugar R, Deasy BM, Badylak S, Buhring HJ, Giacobino JP, Lazzari L, Huard J, Peault B: A perivascular origin for mesenchymal stem cells in multiple human organs. Cell Stem Cell 2008, 3: 301-313

4. Kramann R, Schneider RK, DiRocco DP, Machado F, Fleig S, Bondzie PA, Henderson JM, Ebert BL, Humphreys BD: Perivascular Gli1+ progenitors are key contributors to injury-induced organ fibrosis. Cell Stem Cell 2015, 16:51-66

5. Hung CF, Wilson CL, Schnapp LM: Pericytes in the lung. Adv Exp Med Biol 2019, 1122:41-58

6. Hung C, Linn G, Chow YH, Kobayashi A, Mittelsteadt K, Altemeier WA, Gharib SA, Schnapp LM, Duffield JS: Role of lung pericytes and resident fibroblasts in the pathogenesis of pulmonary fibrosis. Am J Respir Crit Care Med 2013, 188:820-830

7. Puche JE, Saiman Y, Friedman SL: Hepatic stellate cells and liver fibrosis. Compr Physiol 2013, 3:1473-1492

8. Zeisberg M, Yang C, Martino M, Duncan MB, Rieder F, Tanjore H, Kalluri R: Fibroblasts derive from hepatocytes in liver fibrosis via epithelial to mesenchymal transition. J Biol Chem 2007, 282: 23337-23347

9. Murray IR, Gonzalez ZN, Baily J, Dobie R, Wallace RJ, Mackinnon AC, Smith JR, Greenhalgh SN, Thompson AI, Conroy KP, Griggs DW, Ruminski PG, Gray GA, Singh M, Campbell MA, Kendall TJ, Dai J, Li Y, Iredale JP, Simpson H, Huard J, Peault B, Henderson NC: Alphav integrins on mesenchymal cells regulate skeletal and cardiac muscle fibrosis. Nat Commun 2017, 8:1118

10. Humphreys BD, Lin SL, Kobayashi A, Hudson TE, Nowlin BT, Bonventre JV, Valerius MT, McMahon AP, Duffield JS: Fate tracing reveals the pericyte and not epithelial origin of myofibroblasts in kidney fibrosis. Am J Pathol 2010, 176:85-97

11. Houlihan DD, Mabuchi Y, Morikawa S, Niibe K, Araki D, Suzuki S, Okano H, Matsuzaki Y: Isolation of mouse mesenchymal stem cells on the basis of expression of Sca-1 and PDGFR-alpha. Nat Protoc 2012, 7:2103-2111

12. Arrighi N, Moratal C, Clement N, Giorgetti-Peraldi S, Peraldi P, Loubat A, Kurzenne JY, Dani C, Chopard A, Dechesne CA: Characterization of adipocytes derived from fibro/adipogenic progenitors resident in human skeletal muscle. Cell Death Dis 2015, 6:e1733

13. Joe AW, Yi L, Natarajan A, Le Grand F, So L, Wang J, Rudnicki MA, Rossi FM: Muscle injury activates resident fibro/adipogenic progenitors that facilitate myogenesis. Nat Cell Biol 2010, 12:153-163

14. Wang Y, Xu J, Meyers CA, Gao Y, Tian Y, Broderick K, Peault B, James AW: PDGFRalpha marks distinct perivascular populations with different osteogenic potential within adipose tissue. Stem Cells 2020, 38:276-290

15. Glasson SS, Askew R, Sheppard B, Carito B, Blanchet T, Ma HL, Flannery CR, Peluso D, Kanki K, Yang Z, Majumdar MK, Morris EA: Deletion of active ADAMTS5 prevents cartilage degradation in a murine model of osteoarthritis. Nature 2005, 434: 644-648

16. Glasson SS, Blanchet TJ, Morris EA: The surgical destabilization of the medial meniscus (DMM) model of osteoarthritis in the 129/SvEv mouse. Osteoarthritis Cartilage 2007, 15:1061-1069

17. Lorenz J, Grassel S: Experimental osteoarthritis models in mice. Methods Mol Biol 2014, 1194:401-419

18. Eymard F, Pigenet A, Citadelle D, Tordjman J, Foucher L, Rose C, Flouzat Lachaniette $\mathrm{CH}$, Rouault C, Clement K, Berenbaum F, 
Chevalier X, Houard X: Knee and hip intra-articular adipose tissues (IAATs) compared with autologous subcutaneous adipose tissue: a specific phenotype for a central player in osteoarthritis. Ann Rheum Dis 2017, 76:1142-1148

19. Khan WS, Tew SR, Adesida AB, Hardingham TE: Human infrapatellar fat pad-derived stem cells express the pericyte marker 3G5 and show enhanced chondrogenesis after expansion in fibroblast growth factor-2. Arthritis Res Ther 2008, 10:R74

20. Hindle P, Khan N, Biant L, Peault B: The infrapatellar fat pad as a source of perivascular stem cells with increased chondrogenic potential for regenerative medicine. Stem Cells Trans1 Med 2017, 6:77-87

21. Kang SH, Fukaya M, Yang JK, Rothstein JD, Bergles DE: NG2+ CNS glial progenitors remain committed to the oligodendrocyte lineage in postnatal life and following neurodegeneration. Neuron 2010, 68:668-681

22. Levi B, James AW, Nelson ER, Peng M, Wan DC, Commons GW, Lee M, Wu B, Longaker MT: Acute skeletal injury is necessary for human adipose-derived stromal cell-mediated calvarial regeneration. Plast Reconstr Surg 2011, 127:1118-1129

23. Lee S, Shen J, Pan HC, Shrestha S, Asatrian G, Nguyen A, Meyers C, Nguyen V, Lee M, Soo C, Ting K, James AW: Calvarial defect healing induced by small molecule smoothened agonist. Tissue Eng Part A 2016, 22:1357-1366

24. Siu RK, Zara JN, Hou Y, James AW, Kwak J, Zhang X, Ting K, Wu BM, Soo C, Lee M: NELL-1 promotes cartilage regeneration in an in vivo rabbit model. Tissue Eng Part A 2012, 18:252-261

25. Yahara Y, Takemori H, Okada M, Kosai A, Yamashita A, Kobayashi T, Fujita K, Itoh Y, Nakamura M, Fuchino H, Kawahara N, Fukui N, Watanabe A, Kimura T, Tsumaki N: Pterosin B prevents chondrocyte hypertrophy and osteoarthritis in mice by inhibiting Sik3. Nat Commun 2016, 7:10959

26. Pritzker KP, Gay S, Jimenez SA, Ostergaard K, Pelletier JP, Revell PA, Salter D, van den Berg WB: Osteoarthritis cartilage histopathology: grading and staging. Osteoarthritis Cartilage 2006, 14:13-29

27. Lewis JS, Hembree WC, Furman BD, Tippets L, Cattel D, Huebner JL, Little D, DeFrate LE, Kraus VB, Guilak F, Olson SA: Acute joint pathology and synovial inflammation is associated with increased intra-articular fracture severity in the mouse knee. Osteoarthritis Cartilage 2011, 19:864-873

28. Inomata K, Tsuji K, Onuma H, Hoshino T, Udo M, Akiyama M, Nakagawa Y, Katagiri H, Miyatake K, Sekiya I, Muneta T, Koga H: Time course analyses of structural changes in the infrapatellar fat pad and synovial membrane during inflammation-induced persistent pain development in rat knee joint. BMC Musculoskelet Disord 2019, 20:8

29. Jensen AR, Kelley BV, Mosich GM, Ariniello A, Eliasberg CD, Vu B, Shah P, Devana SK, Murray IR, Peault B, Dar A, Petrigliano FA; Neer Award 2018: Platelet-derived growth factor receptor alpha co-expression typifies a subset of platelet-derived growth factor receptor beta-positive progenitor cells that contribute to fatty degeneration and fibrosis of the murine rotator cuff. J Shoulder Elbow Surg 2018, 27:1149-1161

30. Uezumi A, Ito T, Morikawa D, Shimizu N, Yoneda T, Segawa M, Yamaguchi M, Ogawa R, Matev MM, Miyagoe-Suzuki Y, Takeda S, Tsujikawa K, Tsuchida K, Yamamoto H, Fukada S: Fibrosis and adipogenesis originate from a common mesenchymal progenitor in skeletal muscle. J Cell Sci 2011, 124:3654-3664

31. Stepien DM, Hwang C, Marini S, Pagani CA, Sorkin M, Visser ND, Huber AK, Edwards NJ, Loder SJ, Vasquez K, Aguilar CA,
Kumar R, Mascharak S, Longaker MT, Li J, Levi B: Tuning macrophage phenotype to mitigate skeletal muscle fibrosis. J Immunol 2020, 204:2203-2215

32. Poulet B, Hamilton RW, Shefelbine S, Pitsillides AA: Characterizing a novel and adjustable noninvasive murine joint loading model. Arthritis Rheum 2011, 63:137-147

33. Barboza E, Hudson J, Chang WP, Kovats S, Towner RA, SilasiMansat R, Lupu F, Kent C, Griffin TM: Profibrotic infrapatellar fat pad remodeling without M1 macrophage polarization precedes knee osteoarthritis in mice with diet-induced obesity. Arthritis Rheumatol 2017, 69:1221-1232

34. Kramann R, Goettsch C, Wongboonsin J, Iwata H, Schneider RK, Kuppe C, Kaesler N, Chang-Panesso M, Machado FG, Gratwohl S, Madhurima K, Hutcheson JD, Jain S, Aikawa E, Humphreys BD: Adventitial MSC-like cells are progenitors of vascular smooth muscle cells and drive vascular calcification in chronic kidney disease. Cell Stem Cell 2016, 19:628-642

35. Schneider RK, Mullally A, Dugourd A, Peisker F, Hoogenboezem R, Van Strien PMH, Bindels EM, Heckl D, Busche G, Fleck D, MullerNewen G, Wongboonsin J, Ventura Ferreira M, Puelles VG, SaezRodriguez J, Ebert BL, Humphreys BD, Kramann R: Gli1(+) mesenchymal stromal cells are a key driver of bone marrow fibrosis and an important cellular therapeutic target. Cell Stem Cell 2017, 20: 785-800.e8

36. Biernacka A, Dobaczewski M, Frangogiannis NG: TGF-beta signaling in fibrosis. Growth Factors 2011, 29:196-202

37. Gyorfi AH, Matei AE, Distler JHW: Targeting TGF-beta signaling for the treatment of fibrosis. Matrix Biol 2018, 68-69:8-27

38. Kim KK, Sheppard D, Chapman HA: TGF-beta1 signaling and tissue fibrosis. Cold Spring Harb Perspect Biol 2018, 10

39. Meng XM, Nikolic-Paterson DJ, Lan HY: TGF-beta: the master regulator of fibrosis. Nat Rev Nephrol 2016, 12:325-338

40. Ismaeel A, Kim JS, Kirk JS, Smith RS, Bohannon WT, Koutakis P: Role of transforming growth factor-beta in skeletal muscle fibrosis: a review. Int J Mol Sci 2019, 20:2446

41. Contreras O, Cruz-Soca M, Theret M, Soliman H, Tung LW, Groppa E, Rossi FM, Brandan E: Cross-talk between TGF-beta and PDGFRalpha signaling pathways regulates the fate of stromal fibroadipogenic progenitors. J Cell Sci 2019, 132:jcs232157

42. Contreras O, Brandan E: Fibro/adipogenic progenitors safeguard themselves: a novel mechanism to reduce fibrosis is discovered. J Cell Commun Signal 2017, 11:77-78

43. Mueller AA, van Velthoven CT, Fukumoto KD, Cheung TH, Rando TA: Intronic polyadenylation of PDGFRalpha in resident stem cells attenuates muscle fibrosis. Nature 2016, 540:276-279

44. Iwayama T, Steele C, Yao L, Dozmorov MG, Karamichos D, Wren JD, Olson LE: PDGFRalpha signaling drives adipose tissue fibrosis by targeting progenitor cell plasticity. Genes Dev 2015, 29: $1106-1119$

45. Hardy WR, Moldovan NI, Moldovan L, Livak KJ, Datta K, Goswami C, Corselli M, Traktuev DO, Murray IR, Peault B, March K: Transcriptional networks in single perivascular cells sorted from human adipose tissue reveal a hierarchy of mesenchymal stem cells. Stem Cells 2017, 35:1273-1289

46. Ding L, Vezzani B, Khan N, Su J, Xu L, Yan G, Liu Y, Li R, Gaur A Diao Z, Hu Y, Yang Z, Hardy WR, James AW, Sun H, Peault B: CD10 expression identifies a subset of human perivascular progenitor cells with high proliferation and calcification potentials. Stem Cells 2020, 38:261-275 